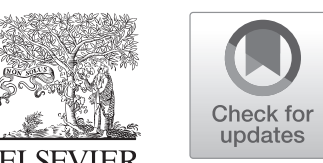

\title{
Ab initio Everolimus-based Versus Standard Calcineurin Inhibitor Immunosuppression Regimen in Liver Transplant Recipients
}

\author{
T.M. Manzia ${ }^{a, \star}$, R. Angelico ${ }^{a, b}$, L. Toti ${ }^{a}$, C. Grimaldi ${ }^{b}$, D. Sforza ${ }^{a}$, I. Vella ${ }^{a}$, L. Tariciotti ${ }^{a}$, I. Lenci ${ }^{\text {, }}$ \\ G. Breshanaj ${ }^{\mathrm{a}}$, L. Baiocchi ${ }^{\mathrm{C}}$, and G. Tisone ${ }^{\mathrm{a}}$
}

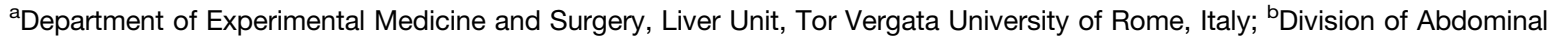
Transplantation and Hepatobiliopancreatic Surgery, Bambino Gesu' Children's Research Hospital IRCCS, Rome, Italy; and ' Department of Hepatology and Gastroenterology, Liver Unit, Tor Vergata University of Rome, Italy

\begin{abstract}
Aim. We designed a retrospective case-control study to determine the efficacy and feasibility of everolimus (EVR) combined with low-dose tacrolimus (Tac) ab initio versus standard-dose Tac after liver transplantation (LT).

Methods. Seventy-one adult LT patients, receiving EVR and low-dose Tac without corticosteroids or induction therapy from postoperative day 1 (EVR group) were compared with a well-matched control group of 61 recipients treated with standard-dose Tac in association with antimetabolite.

Results. Baseline characteristics for the two groups were comparable. The overall patient and graft survival rates were similar $(P=.908)$. Liver function was stable during the followup. In the EVR group, biopsy-proven acute rejection occurred in two cases $(2.8 \%)$, whereas chronic rejection occurred in one $(1.4 \%)$. The EVR group experienced a better renal function already after 2 weeks (estimated glomerular filtration rate: 89.85 [36.46 to $115.3] \mathrm{mL} / \mathrm{min} / 1.73 \mathrm{~m}^{2}$ vs. 68.77 [16.11 to 115.42$] \mathrm{mL} / \mathrm{min} / 1.73 \mathrm{~m}^{2} ; P=.013$ ), which was also observed after a median time of 27 months (range, 0 to 82 months) from LT (estimated glomerular filtration rate: 80 [45 to 118.3$] \mathrm{mL} / \mathrm{min} / 1.73 \mathrm{~m}^{2}$ vs. 70.9 [45 to $\left.88.4] \mathrm{mL} / \mathrm{min} / 1.73 \mathrm{~m}^{2} ; P=.04\right)$. After a median time of 27 months, the EVR group showed lower incidence of arterial hypertension and insulin-dependent diabetes mellitus.

Conclusion. Ab initio EVR-based immunosuppression could be a valid option immediately after surgery in recipients at high-risk for post-LT renal impairment.
\end{abstract}

$\mathbf{T}$ EE goal of immunosuppression (IS) in liver transplantation (LT) is to maintain graft function with a low grade of acute rejection while minimizing drug-related adverse effects. Calcineurin inhibitors (CNIs) are the main immunosuppressant therapy used to prevent acute rejection after LT, but it is well known that prolonged exposure to CNIs was associated with short- and long-term side effects, including nephrotoxicity [1,2], neurotoxicity [3], increased risk of malignancies [4,5], hypertension, and metabolic complications [6,7].

Therefore, nowadays the objective is to identify an optimal IS regimen to be personalized in the single recipient, preventing rejection and reducing IS-adverse events. Strategies such as dose reduction or delayed introduction of CNIs in association with other IS drugs have been explored in an attempt to decrease the occurrence of IS-related morbidities.

Everolimus (EVR), a mammalian target of rapamycin inhibitor (mTORi), in combination with reduced-dose of tacrolimus (Tac), has been widely used as immunosuppressive agent in maintenance LT recipients [8]. The use of mTORi is a well-established strategy to facilitate the safe reduction or withdrawal of CNIs to preserve renal function over the long-term after transplantation [9-11].

*Address correspondence to Tommaso Maria Manzia, MD, $\mathrm{PhD}$, University of Rome Tor Vergata, Viale Oxford 81, Rome 00133, Italy. E-mail: tomanzia@libero.it

$0041-1345 / 17$ https://doi.org/10.1016/j.transproceed.2017.12.018 
However, the early post-transplantation use (i.e., within 30 days) of EVR has been explored only in a limited number of studies [12-17]. In 2006 a phase 2 study had shown the safety and efficacy of EVR use from post-transplantation day 1, in association with a low dose of CNIs (namely, cyclosporine) and corticosteroids [18]. Whereas in a recent proof-ofconcept study, we have shown the 1-year post-LT safety of corticosteroid-free mTORi use immediately after LT in a group of LT recipients treated without induction and with low doses of CNIs [19]. To retrospectively investigate the longterm efficacy and feasibility of EVR in LT, we now compared our cohort of LT recipients who received mTORi immediately after transplantation with a matched cohort of patients who were treated with standard Tac exposure.

\section{MATERIAL AND METHODS Study Design}

We reviewed a prospectively collected database of the records of all adults who underwent LT between September 2009 and June 2015 at our institution.

The EVR group was composed of recipients who were treated with EVR (Certican, Novartis, Basel, Switzerland) associated with low-dose of once-daily prolonged-release Tac (Advagraf, Astellas, Tokyo, Japan) from postoperative day (POD) 1. The decision to use EVR ab initio was chosen to mitigate Tac exposure in recipients with potentially CNI-related side-effects (i.e., mild preoperative hyperglycemia, mild renal impairment at LT [i.e, following our laboratory upper limit serum creatinine value $>106.08 \mu \mathrm{mol} / \mathrm{L}]$ or previous hepatorenal syndrome) which may deteriorate with standard-Tac exposure, and also in recipients with hepatocellular carcinoma within Milan criteria after down staging [19]. The study group was compared with a matched control group who received standard once-daily prolonged-release Tac exposure (Advagraf), in combination with antimetabolites (mycophenolic acid [Myfortic, Novartis] and mycophenolate mofetil [MMF] [CellCept, Roche, Basel, Switzerland]), according to a previous multicentric study [20]. The matching criteria adopted are summarized in Table 1. Exclusion criteria included recipients in treatment with EVR associated with cyclosporine and/or antimetabolite (AntiM) monotherapy, administration of EVR after the POD 1, simultaneous liver and kidney transplantation, re-LT, and patients who died within 24 hours of LT who could not receive IS drugs.

The endpoint of the study was to compare the efficacy of steroidfree EVR-based IS therapy combined with low-Tac exposure versus standard Tac exposure. The local ethics committee of our institution approved the study.

\section{IS Regimen}

As local policy, in the EVR group, the drug target blood levels were 2 to $5 \mathrm{ng} / \mathrm{mL}$ and 3 to $5 \mathrm{ng} / \mathrm{mL}$ for EVR and Tac, respectively, within the first week. At day 1, the starting dose of EVR was 0.015 $\mathrm{mg} / \mathrm{kg} / \mathrm{d}$. Once-daily prolonged-release Tac was started at a dose of $0.05 \mathrm{mg} / \mathrm{kg} / \mathrm{d}$ from POD 1. No patients received corticosteroids or induction therapy.

In the control group, the IS therapy was based from POD 1 on standard dose of once-daily prolonged-release Tac $(0.175 \mathrm{mg} / \mathrm{kg} / \mathrm{d})$ combined with MMF $2000 \mathrm{mg} / \mathrm{d}$ or enteric-coated mycophenolate sodium $1440 \mathrm{mg} / \mathrm{d}$. Patients also received basiliximab $(20 \mathrm{mg})$ on PODs 0 and 4.
Table 1. Recipients, Donors and Surgical Characteristics of the Two Groups at Baseline.

\begin{tabular}{|c|c|c|c|}
\hline Variables & EVR & Control & $P$ Value \\
\hline Patients & 71 & 61 & \\
\hline Age (yrs) & $58(25-67)$ & $52(34-65)$ & .397 \\
\hline Male (\%) & 55 (77.5\%) & 49 (80.3\%) & .831 \\
\hline BMI & $25(16-30)$ & $24(18-32)$ & .861 \\
\hline MELD score at LT & $19(11-26)$ & $20(7-31)$ & .265 \\
\hline Donor age (years) & $57(6-79)$ & $65(15-83)$ & .645 \\
\hline CIT (minutes) & $447(240-721)$ & $402(235-520)$ & .739 \\
\hline WIT (minutes) & $45(32-70)$ & $40(20-105)$ & .466 \\
\hline \multicolumn{4}{|l|}{ Indications to LT } \\
\hline HCV-related cirrhosis & $14(19.8 \%)$ & 7 (11.5\%) & .237 \\
\hline HCC-T2 & $24(33.8 \%)$ & $25(40.9 \%)$ & .471 \\
\hline $\begin{array}{l}\text { HCC-T2 after } \\
\text { down staging }\end{array}$ & $24(100 \%)$ & $12(48 \%)$ & .04 \\
\hline HBV-related cirrhosis & $6(8.4 \%)$ & $4(6.6 \%)$ & .751 \\
\hline Alcoholic cirrhosis & $13(18.2 \%)$ & $14(23 \%)$ & .524 \\
\hline Autoimmune liver dise & $1(1.4 \%)$ & - & 1.000 \\
\hline Cryptogenetic liver disease & $3(4.2 \%)$ & $5(8.2 \%)$ & .470 \\
\hline NASH & $2(2.8 \%)$ & - & 499 \\
\hline Budd-Chiari syndrome & - & $1(1.6 \%)$ & 1.000 \\
\hline Wilson's disease & $1(1.4 \%)$ & $1(1.6 \%)$ & 1.000 \\
\hline $\begin{array}{l}\text { Primary sclerosing } \\
\text { cholangitis }\end{array}$ & $7(9.8 \%)$ & $3(4.92 \%)$ & .339 \\
\hline $\begin{array}{l}\text { Polycystic liver disease } \\
\text { Comorbidities pre- } L T\end{array}$ & - & $1(1.6 \%)$ & 1.000 \\
\hline IDDM & $9(12.7 \%)$ & $12(19.7 \%)$ & .342 \\
\hline Cardiovascula & $4(5.6 \%)$ & $3(4.9 \%)$ & .855 \\
\hline Arterial hypertension & 9 (12.9\%) & $6(9.8 \%)$ & .784 \\
\hline Hypercholesterolemia & $1(1.4 \%)$ & - & 1.000 \\
\hline Hypertriglyceridemia & $2(2.8 \%)$ & $3(4.9 \%)$ & .662 \\
\hline
\end{tabular}

Values reported as medians and ranges, nonparametric data compared with Mann-Whitney $U$ test; $P<.05=$ significant

Abbreviations: EVR, everolimus; BMI, body mass index; MELD, Model of Endstage Liver Disease; LT, liver transplantation; CIT, cold ischaemia time; WIT, warm ischaemia time; HCV, hepatitis C virus; $\mathrm{HCC}$ T2, hepatocellular carcinoma type 2; HBV, hepatitis B virus; NASH, nonalcoholic steatohepatitis; IDDM, insulin-dependent diabetes mellitus.

Measurement of EVR and Tac blood trough levels were assayed on a liquid chromatography coupled to tandem mass spectrometry analyzer in both groups [21].

\section{Graft and Renal Function}

Graft and renal function were evaluated by liver and renal function tests as routine practice (i.e., assessing liver function tests [LFT] and estimated glomerular filtration rate [eGFR]) at first posttransplantation week, at POD 15, months 1, 3, 6, 12, and 24, and at last follow-up available.

Graft rejection was diagnosed by liver biopsy according to Banff criteria [22]. As for local protocol, liver biopsies were performed only if clinical examinations and laboratory tests (defined as increasing of aspartate aminotransferase [AST] or alanine aminotransferase $[\mathrm{ALT}]>2$-fold baseline levels and/or in both gamma-glutamyltransferase [GGT] and AP > 1.5-fold baseline levels) were suggestive of acute cellular rejection (ACR). The severity of ACR was classified as indeterminate, mild, moderate, or severe, as well as chronic rejection [23]. Biopsies were also scored for the grade of necro-inflammatory activity and stage of fibrosis according to Ishak et al [24]. Hepatitis C virus (HCV)-infected recipients underwent protocol liver biopsies at 6 months and 1 year 
from LT. All liver biopsy specimens were evaluated by experienced LT histopathologists.

\section{Evaluation of Adverse Events}

All drug-related adverse events were considered, including: 1) newonset insulin-dependent diabetes mellitus (IDDM), diagnosed for insulin therapy for $\geq 30$ consecutive days [25]; 2) hyperlipidemia (defined as serum cholesterol $>6.2 \mathrm{mmol} / \mathrm{L}$ and/or triglycerides $>1.69 \mathrm{mmol} / \mathrm{L}$ ); 3) leukopenia (defined as a white blood cell count of $<2000 / \mu \mathrm{L}$ ); 4) infection requiring specific treatment; 5) wound dehiscence; 6) cardiovascular events; 7) new onset of arterial hypertension (defined as systolic blood pressure $>140 \mathrm{~mm} \mathrm{Hg}$ and/ or diastolic blood pressure $>90 \mathrm{~mm} \mathrm{Hg}$ who require hypotensive medications); 8) de novo tumors; and 9) thrombotic vascular complications (e.g., hepatic artery thrombosis).

\section{Statistical Analysis}

Data were collected from a prospectively collected consecutive database (Microsoft Access 2.0; Microsoft Corporation, Redmond, Washington, United States). Donor/recipient characteristics and clinical data are shown (wherever applicable) as either median with range or mean \pm standard deviation. Univariate data were analyzed using the Mann-Whitney test and Fisher's exact test. A $P$ value of $<.05$ was considered significant. Normal distribution continuous data were analyzed by parametric test (Student $t$ test). Survival rates were calculated using the Kaplan-Meier method. The software used for statistical analysis was SPSS 13.0 for Windows (Chicago, Illinois, United States).

\section{RESULTS}

Patient Population and Survival

A total of 179 LTs were performed during the study period; the median study follow-up was 27 months (range, 0 to 82 months) Seventy-one $(\mathrm{n}=71 ; 39.7 \%)$ nonconsecutive LT recipients $(\mathrm{n}=55$ males, median age 58 years [range, 25 to 67 years]) were treated with EVR associated with low Tac exposure from the POD 1 and formed the EVR group. The control group consisted of 61 nonconsecutive recipients ( $\mathrm{n}=49$ males, median age 52 years [range, 34 to 65 years]) who received standard Tac exposure and antimetabolites immediately after LT (Fig 1). Recipients, donors, and surgical variables were comparable in the two groups (Table 1).

The overall patient and graft survival rates in the EVR and control groups were $78 \%$ versus $79 \%(P=.908)$, respectively (Fig 2). The causes of death are summarized in Table 2.

\section{Liver Function Profile}

The LFT peaks (defined as the highest value recorded within the first post-transplant week) were comparable in

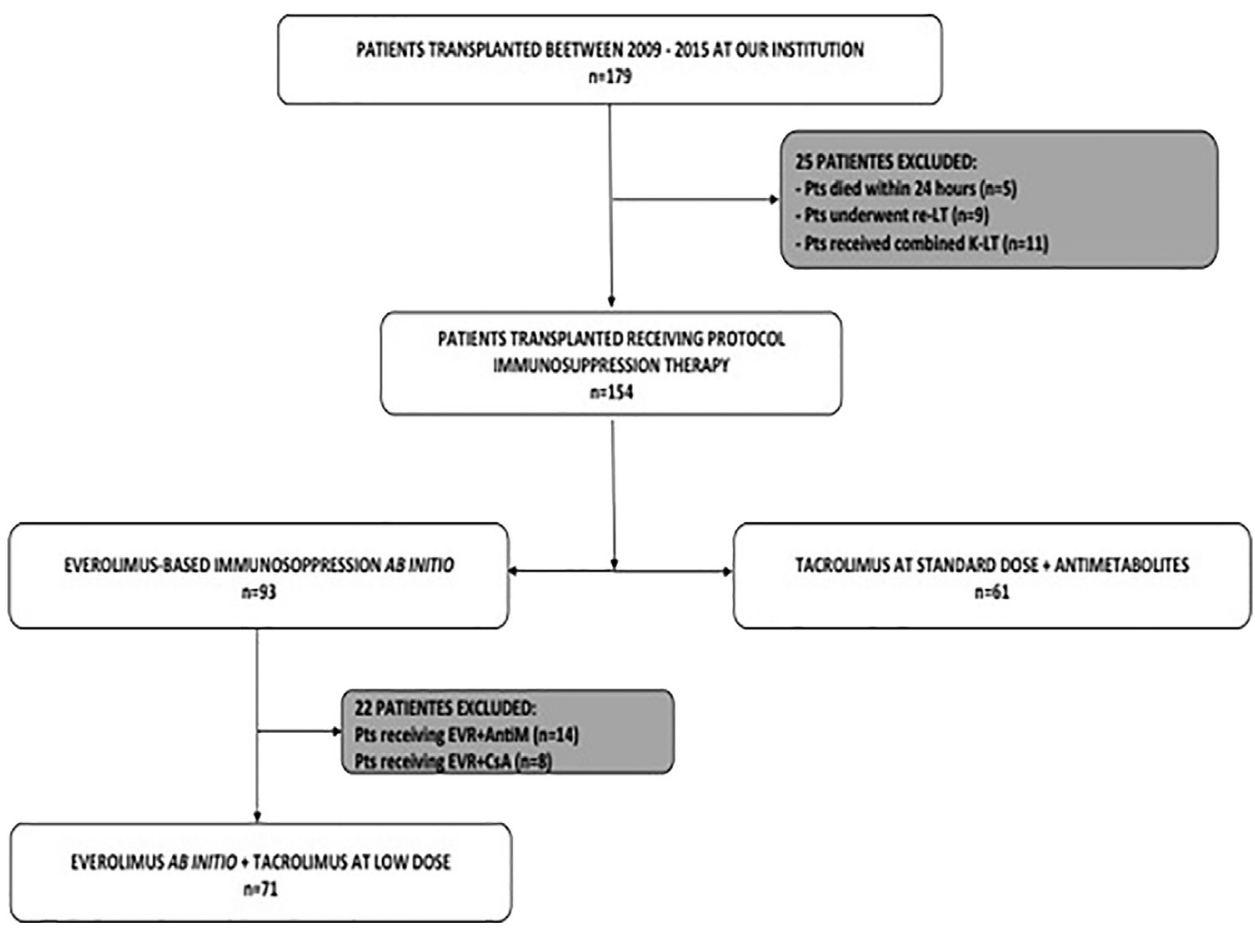

Fig 1. Selection process of the study group and the well-matched control group. The study group (EVR group) consisted in $71 \mathrm{LT}$ recipients receiving immunosuppression based on EVR + low dose of tacrolimus ab initio (from postoperative day 1). The EVR group was then compared with a well-matched control group $(n=61)$ represented by all patients receiving a LT in the same period at our institution, treated with standard dose of tacrolimus combined with antimetabolites. Abbreviations: LT, liver transplant; EVR, everolimus; Pts, patients; AntiM, antimetabolites; CsA, cyclosporine. 


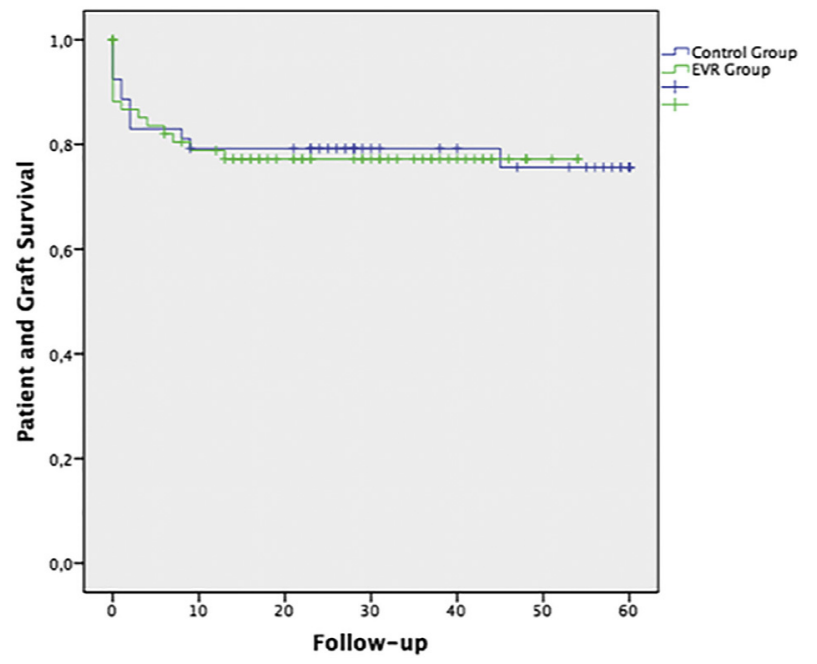

Fig 2. Overall patient and graft survival in the two groups. Graft and patient survival in patients who received EVR-based immunosuppression ab initio combined with low dose of $\mathrm{CNI}$ ( $\mathrm{n}=71$, EVR group) versus patients who received standard dose of $\mathrm{CNI}$ with antimetabolites ( $n=61$, Control group) after liver transplantation. Abbreviations: EVR, everolimus; CNI, calcineurin inhibitor.

the two groups as described in Table 2. One month after LT, AST values (35 [4-462] IU/L in the EVR group vs 27 [6-206] $\mathrm{IU} / \mathrm{L}$ in the control group, $P=.165$ ) and ALT values (55 [10-539] IU/L in the EVR group vs. 35 [4-462] IU/L in the control group, $[P=.358])$ were similar and remained stable over the entire follow-up. There were no significant variations also for GGT $(P=.281)$ (Fig 3). In the EVR group, two $(2.8 \%)$ patients developed biopsy-proven moderate ACR 1 month after LT and one (1.4\%) recipient presented chronic rejection at the 28-month follow-up. In the control group, two $(3.3 \%)$ recipients experienced moderate ACR after 3 months and 1 year, respectively $(P=1.000)$. All HCV-recipients who had liver biopsies for local policy, none showed signs of rejection.

\section{Renal Function}

Details of renal function for both groups during the entire follow-up period are reported in Fig 4. At the time of transplantation none of the patients were in hemodialysis and the median eGFR was similar. The EVR group showed superior renal function compared to the control group after 2 weeks from surgery and throughout the entire follow-up period.

During post-LT hospitalization, $3(4.2 \%)$ patients in the EVR group versus $5(9.2 \%)(P=.876)$ in the control group experienced acute kidney failure requiring hemodialysis. Moreover, in the control group, long-term dialysis (i.e., patients who required dialysis for a period of $>3$ months) was needed for $3(4.9 \%)$ LT recipients, whereas none of the EVR group needed long-term renal support. Of the 8 recipients who experienced renal impairment, three died (two from the control group and one from the EVR group);
Table 2. Overall Follow up of the EVR and Control Groups

\begin{tabular}{|c|c|c|c|}
\hline Variables & $\begin{array}{c}\text { EVR } \\
(n=71)\end{array}$ & $\begin{array}{l}\text { Control } \\
(\mathrm{n}=61)\end{array}$ & $P$ \\
\hline Median Follow-up (mo) & $30(0-82)$ & $24(0-54)$ & .568 \\
\hline \multicolumn{4}{|l|}{ Peak LFTs } \\
\hline AST (IU/L) & $1085(410-7769)$ & $962(85-10,926)$ & .345 \\
\hline ALT (IU/L) & 832 (194-4391) & $905(105-3810)$ & .484 \\
\hline Total bilirubin (mg/dL) & $6.2(1.8-21.7)$ & $3.27(1.3-9.85)$ & .496 \\
\hline \multicolumn{4}{|l|}{ LFTs at last follow-up } \\
\hline AST (IU/L) & $20(10-75)$ & $26(13-218)$ & .823 \\
\hline ALT (IU/L) & $31(10-256)$ & $31(6-169)$ & .943 \\
\hline Total bilirubin (mg/dL) & $0.5(0.2-5.93)$ & $0.72(0.3-5.7)$ & .134 \\
\hline Total number of deaths & $16(22 \%)$ & $15(24 \%)$ & 1.000 \\
\hline \multicolumn{4}{|l|}{ Cause of death } \\
\hline HCC recurrence & $2(2.8 \%)$ & $2(3.3 \%)$ & 1.000 \\
\hline Other tumor & & $2(3.3 \%)$ & \\
\hline PNF & $3(4.22 \%)$ & - & 249 \\
\hline Sepsis & $5(7.04 \%)$ & $5(8.2 \%)$ & 1.000 \\
\hline Respiratory failure & $2(2.82 \%)$ & $3(4.92 \%)$ & .662 \\
\hline Myocardial ischemia & 2 (2.8\%) & $1(1.64 \%)$ & 1.000 \\
\hline $\begin{array}{l}\text { Complicated } \\
\text { pancreatitis }\end{array}$ & $1(1.41 \%)$ & 2 (3.28\%) & .595 \\
\hline Cerebral ischemia & $1(1.41)$ & - & 1.000 \\
\hline \multicolumn{4}{|l|}{ Adverse events } \\
\hline Leukopenia & $3(4.22 \%)$ & $4(6.5 \%)$ & .530 \\
\hline IDDM & $10(14 \%)$ & $19(31.7 \%)$ & $.021^{\star}$ \\
\hline New-onset IDDM & $4(5.6 \%)$ & 7 (11.47\%) & .344 \\
\hline $\begin{array}{l}\text { New-onset arterial } \\
\text { hypertension }\end{array}$ & $11(15.4 \%)$ & $21(34.4 \%)$ & $.001^{*}$ \\
\hline Hypertriglyceridemia & $15(21 \%)$ & $10(16.3 \%)$ & .391 \\
\hline Hypercholesterolemia & $11(15.4 \%)$ & 9 (14.8\%) & .391 \\
\hline Recurrent infections & $13(18.3 \%)$ & $17(27.9 \%)$ & .193 \\
\hline $\begin{array}{l}\mathrm{CMV} \text { infection } \\
\quad \text { requiring treatment }\end{array}$ & $6(8.5 \%)$ & $6(9.8 \%)$ & 1.000 \\
\hline $\begin{array}{l}\text { Cardiovascular } \\
\text { disease }\end{array}$ & $2(2.8 \%)$ & $6(9.8 \%)$ & .093 \\
\hline Wound dehiscence & $8(11.3 \%)$ & $4(6.6 \%)$ & .383 \\
\hline HCC recurrence & $2(2.8 \%)$ & $2(3.3 \%)$ & .383 \\
\hline Tumor de novo & $2(2.8 \%)$ & $5(8.2 \%)$ & .181 \\
\hline $\begin{array}{l}\text { Hepatic artery } \\
\text { thrombosis }\end{array}$ & $2(2.8 \%)$ & - & 1.000 \\
\hline Dyspepsia & 0 & $4(6.6 \%)$ & .134 \\
\hline $\begin{array}{c}\text { Therapy at last } \\
\text { follow-up }\end{array}$ & (Alive: 55) & (Alive: 46) & \\
\hline EVR monotherapy & $8(13 \%)$ & $5(10.8 \%)^{*}$ & \\
\hline $\begin{array}{l}\text { Tacrolimus } \\
\text { monotherapy }\end{array}$ & $5(9.3 \%)$ & $18(39 \%)$ & \\
\hline EVR + tacrolimus & $40(74 \%)$ & $6(13 \%)^{\dagger}$ & \\
\hline Tacrolimus + AntiM & $2(3.7 \%)$ & $17(36.9 \%)$ & \\
\hline
\end{tabular}

Values reported as medians and ranges, nonparametric data compared with Mann-Whitney $U$ test; $P<.05=$ significant.

Abbreviations: EVR, everolimus; LFT, liver function test; AST, aspartate aminotransferase; ALT, alanine aminotransferase; HCC, hepatocellular carcinoma; PNF, primary nonfunction; IDDM, insulin dependent diabetes mellitus; CMV, cytomegalovirus; AntiM, antimetabolites.

*During follow up, five recipients were treated with Everolimus monotherapy because de novo tumor occurred.

${ }^{\dagger}$ Antimetabolites were switched to everolimus because dyspepsia (n.4) and HCC recurrence (n.2) occurred.

one died from myocardial ischemia, and 2 from respiratory failure. Five patients recovered after the Tac dose was decreased. 


\section{$\operatorname{ALT}(I U / L)$}

EVR group $\quad$ Control group

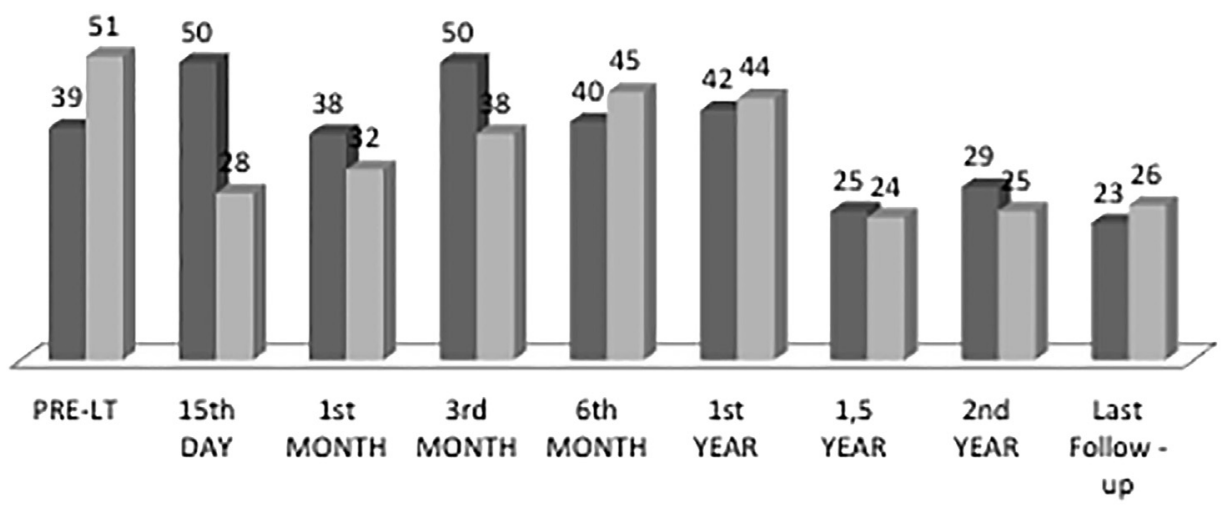

GAMMA -GT(IU/L)

EVR group Control group

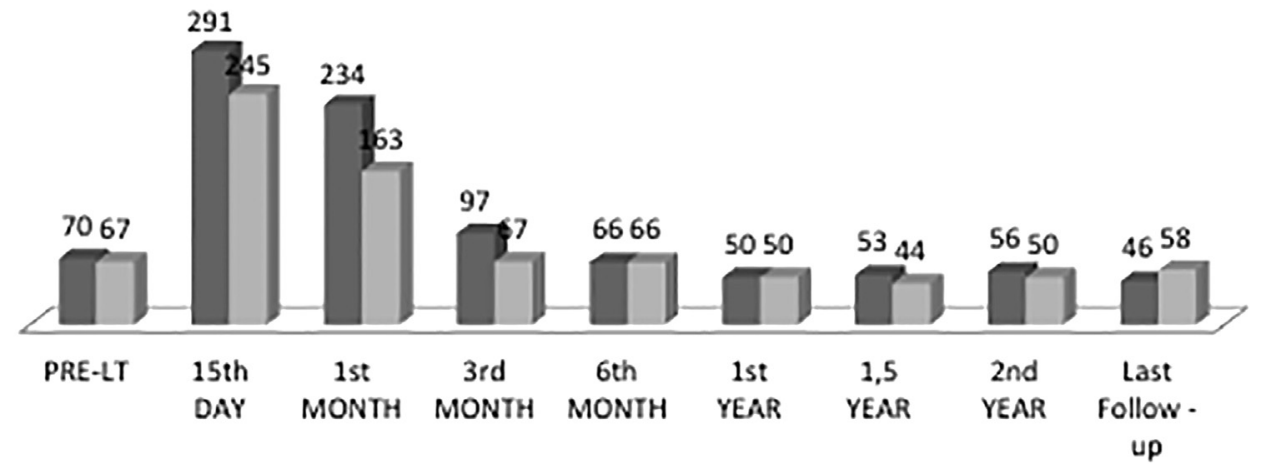

Fig 3. Median blood levels after transplantation of alanine aminotransferase and gamma-glutamyltransferase. Abbreviations: LT, liver transplantation; EVR, everolimus; GAMMA-GT, gamma-glutamyltransferase (IU/L); ALT, alanine aminotransferase (IU/L).

\section{Immunosuppressive Regimen}

EVR trough level and doses are reported in Fig 5. The median EVR blood concentration at month 1 after LT was $2.41 \mathrm{ng} / \mathrm{mL}$ (range, 1.09 to $7.40 \mathrm{ng} / \mathrm{mL}$ ), and no significant variation of trough levels was observed during the entire observational period $(P=.121)$. The median EVR daily dose during the follow-up period was $1 \mathrm{mg} / \mathrm{d}$ (range, 0.25 to $4 \mathrm{mg} / \mathrm{d})$. The median Tac trough level was $4.95 \mathrm{ng} / \mathrm{mL}$ (range, 1.41 to $6.81 \mathrm{ng} / \mathrm{mL}$ ) and was maintained by adjusting the dosage for the entire period. At last follow-up, 9 of $71(12 \%)$ had a Tac trough level $>5 \mathrm{ng} / \mathrm{mL}$.

In the control group, the starting dose of Tac was $8 \mathrm{mg}$ / d (range, 2 to $22 \mathrm{mg} / \mathrm{d}$ ), with a trough blood level of $8.5 \mathrm{ng} / \mathrm{mL}$ (range, 4.04 to $13.5 \mathrm{ng} / \mathrm{mL}$ ) after 1 month from OLT. No significant variation in Tac daily dose and blood level were observed during the entire follow-up. MMF was administered in $44(72 \%)$ recipients (median dose $2000 \mathrm{mg} / \mathrm{d}$ [range, 1000 to $2000 \mathrm{mg} / \mathrm{d}$ ), whereas entericcoated mycophenolate sodium was administered in 16 (28\%) patients (median dose $1080 \mathrm{mg} / \mathrm{d}$ [range, 720 to $1440 \mathrm{mg} / \mathrm{d}$ ) from the POD 1.

\section{Adverse Events}

Drug-related toxicities are described in Table 2. During the entire follow-up, evidence of leukopenia was observed in three $(4.9 \%)$ patients in control group versus two $(2.8 \%)$ in the EVR group $(P=.530)$, and there were no cases of thrombocytopenia. All events were resolved by dose reduction of EVR or AntiM, with the only exception of one patient who required EVR withdrawal.

Four recipients $(5.6 \%)$ in EVR group and 7 (11.5\%) in the control group developed new onset IDDM after LT 


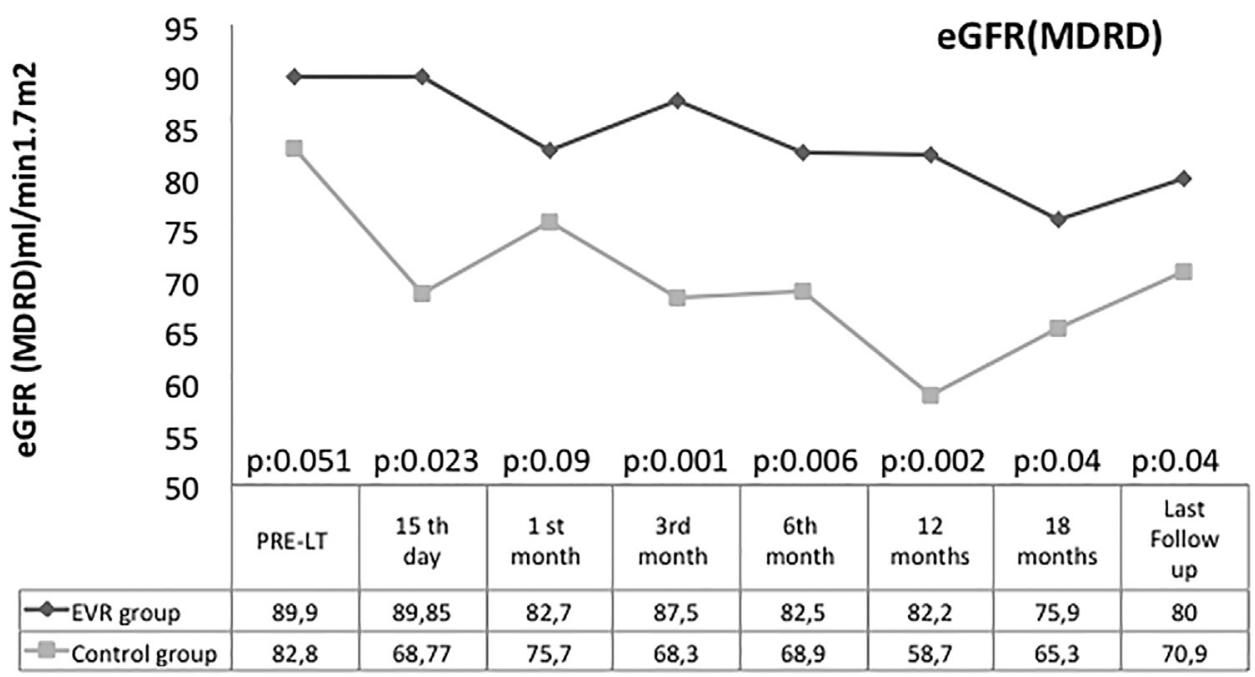

Fig 4. Median glomerular filtration rate (MDRD formula) from LT to last follow-up in the EVR group and control group. Abbreviations: eGFR, estimated glomerular filtration rate; MDRD, Modification of Diet in Renal Disease; LT, liver transplant; EVR, everolimus.

$(P=.344)$. Of the nine patients in the EVR group who had IDDM before LT, three recipients were able to discontinue insulin therapy after LT. In contrast, none of the patients in the control group discontinued insulin therapy. At the last follow-up, $10(14.1 \%)$ patients in the study group and 19 $(31.7 \%)$ in the control group required insulin treatment $(P=.021)$.

The median level of cholesterol was similar in the two groups during the entire observational period, and increased in both groups at the last follow-up (EVR group: $3.2 \mathrm{mmol} / \mathrm{L}$ [range, 1.24 to $6.1 \mathrm{mmol} / \mathrm{L}$ ] at baseline and 4.71 $\mathrm{mmol} / \mathrm{L}$ [range, 1.65 to $8.15 \mathrm{mmol} / \mathrm{L}$ ] after a median time of 27 months $[P=.00002]$; control group: $3.1 \mathrm{mmol} / \mathrm{L}$ [range, 1.3 to $5.1 \mathrm{mmol} / \mathrm{L}$ ] at baseline vs. $4.32 \mathrm{mmol} / \mathrm{L}$ [range, 2.07 to $5.46 \mathrm{mmol} / \mathrm{L}]$ at last follow-up $[P=.00001])$. Similarly, the median triglyceride blood level increased significantly at the last follow-up both in the EVR group (from $0.9 \mathrm{mmol} / \mathrm{L}$ [range, 00.44 to $2.41 \mathrm{mmol} / \mathrm{L}$ ] to $2.11 \mathrm{mmol} / \mathrm{L}$ [range, 0.73 to

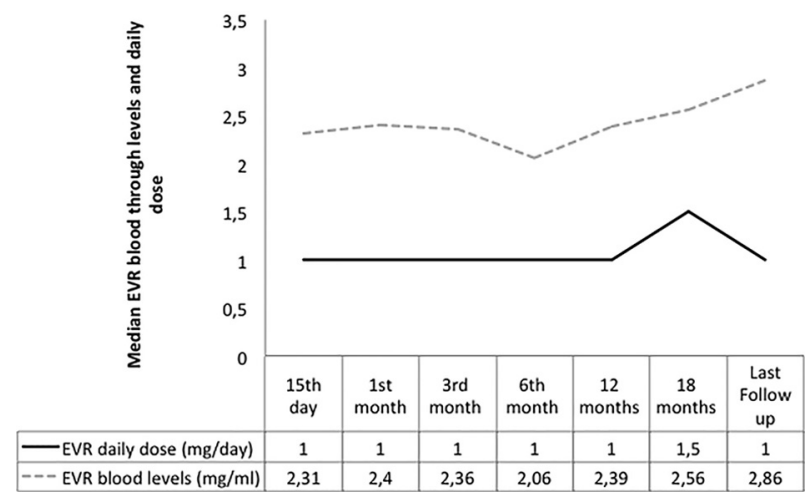

Fig 5. Median everolimus blood trough levels and daily dose throughout the entire observation period. Abbreviations: EVR, everolimus.
$3.51 \mathrm{mmol} / \mathrm{L}][P=.0001]$ ) and in the control group (from $0.94 \mathrm{mmol} / \mathrm{L}$ [range, 0.37 to $3 \mathrm{mmol} / \mathrm{L}$ ] to $1.62 \mathrm{mmol} / \mathrm{L}$ [range, 0.73 to $3.63 \mathrm{mmol} / \mathrm{L}][P=.0012])$. The number of patients requiring treatment for hyperlipidemia was similar in both groups (10 [14.1\%] patients in EVR group vs. 4 [6.5\%] patients in the control group, $[P=.160])$.

New-onset arterial hypertension was significantly higher in patients treated with a standard dose of Tac compared to those receiving an EVR-based regimen with low-dose Tac $(\mathrm{n}=21[34.4 \%]$ vs. $\mathrm{n}=8$ [11.3\%], respectively; $P=.002)$.

\section{DISCUSSION}

The identification of "tailored" IS regimens is a challenge for transplantation science. The choice of an optimal regimen is a key point to balance low rejection and IS adverse events. In the last decades, the CNI-based immunosuppressive regimen has been the most common therapy worldwide, despite the well-known dose- and time-related side effects, including acute and chronic renal dysfunction, cardiovascular disease, increased malignancies, and metabolic disorders [1-7].

Current strategies to reduce IS adverse events are focused on delaying introduction or reducing dose exposure to CNIs by combining them with different drugs. In this regard, the introduction of new immunosuppressive drugs, such as EVR, has allowed the individual tailoring of IS regimens after LT based on specific recipient CNI comorbidities.

EVR has recently been approved by the Food and Drug Administration as a new immunosuppressive agent in patients receiving $\mathrm{LT}$, in combination with Tac and steroids [8]. Until now, mTORi-based regimens have been commonly adopted in long-term recipients to withdraw or minimize the exposure to cyclosporine or Tac, with the principal aim of improving long-term renal function after organ transplantation [26]. 
In maintenance $\mathrm{LT}$ recipients, the efficacy and safety of conversion from CNIs to EVR have been intensely investigated [27]. In a randomized, open-label, multicenter study, 145 long-term LT recipients with CNI-related renal dysfunction were randomized either to start EVR with CNI reduction/discontinuation or to continue standard exposure to CNI regimen: EVR monotherapy was achieved in $85 \%$ of patients with very low rates of biopsy-proven ACR [28]. However, in this trial no benefits were reported in terms of renal function, probably due to the lengthy exposure to CNI, which may lead to interstitial fibrosis and glomerular obliteration due to prolonged vasoconstriction of renal microcirculation [29]. This hypothesis was confirmed by the larger study on the use of mTORi in kidney transplantation, in which the conversion from CNI-based therapy to EVR or sirolimus in patients with baseline eGFR $<50 \mathrm{~mL} / 1.73 \mathrm{~m}^{2}$ reported no improvement in renal function [30,31]. Recently, a national working group recommended the use of EVR in predefined clinical scenarios, especially in LT recipients with high risk of post-transplantation nephrotoxicity and long-term CNIs adverse events [32].

The early introduction of EVR after LT was first described by Masetti et al in 2010 [15], showing a significant improvement in renal function after EVR introduction versus the controls under a standard CNI regimen (eGFR: $87.7 \pm 26.1 \mathrm{~mL} / \mathrm{min}$ vs. $59.9 \pm 12.6 \mathrm{~mL} / \mathrm{min} ; P=.001)$. More recently, the PROTECT study randomized patients after 30 post-transplantation days to continue a CNI-based regimen or start EVR with CNI discontinuation [10]. Results showed that the conversion was achieved safely because biopsy-proven ACR rates were similar, with beneficial effects on renal function.

Later, the larger cohort of the H2304 open-label randomized trial confirmed that after 1 month, the EVR with Tac discontinuation arm was associated with a high rate of mild ACR, which led to premature termination of patient enrolment [9]. The authors concluded that mTORi regimen without induction therapy or other IS drugs might not be a viable option until 3 months after LT. Yet, the same authors reported that EVR introduction with reduced-exposure to Tac after 1 month from LT provides a significant benefit to renal function after 2 years of follow-up [33]. Moreover, recently De Simone et al showed that the efficacy of early EVR introduction with reduced Tac exposure is maintained even in recipients with high-risk factors for graft rejection (e.g., younger and HCV-positive recipients) and chronic renal failure [34].

All studies mentioned above reported the early introduction (within 30 post-transplantation days) of EVR in de novo LT [12-17], but only Levy et al [18] have shown good safety, tolerability, and efficacy of the EVR-based regimen with corticosteroids from the "very" first day post-transplantation.

To the best of our knowledge, the current study is the first report that compares the use of a steroid-free EVR-based IS regimen with low-dose Tac, adopted from the first posttransplantation day, with standard Tac-based IS. Our results show that EVR-based therapy is safe and effective, even when used without corticosteroids or induction therapy. Recipients treated with EVR ab initio had graft and patient survival rates comparable to those receiving a standard Tac dose. In the study population, only three $(4.2 \%)$ LT recipients presented increased LFTs requiring liver biopsy, which confirmed rejection. The absence of subclinical rejection episodes was confirmed by the HCV-positive graft protocol biopsy specimens at 6 and 12 months after LT, which did not show any histologic sign of rejection. We believe that the low rate of ACR was mainly due to the judicious adjustment of EVR dose administration based on the careful drug trough blood monitoring during the entire follow-up period. This concept is also in line with data reported in a recent review on the optimal exposure range of EVR (defined as 3 to $8 \mathrm{ng} / \mathrm{mL}$ ) in combination with reduced-exposure CNI therapy [35].

Moreover, Willuweit et al recently reported that receiving mTORi as an IS regimen after LT is a protective factor against the development of donor-specific antibodies, which could potentially represent an additional benefit for the immunological profile in the post-transplantation setting [36].

In our study, LT recipients treated with EVR ab initio maintained a stable renal function with no cases of chronic renal dysfunction, whereas kidney function worsened in the control group. These results confirm data from a French experience, suggesting that EVR should be introduced as soon as possible after LT to reduce exposure to high doses of CNIs to preserve the renal function [37]. Therefore, it is conceivable that the administration of EVR from the first post-operative day may be particularly beneficial in patients experiencing renal impairment while on the waiting list or early after LT, decreasing the incidence of chronic renal failure in future [31,38-40]. Moreover, a recent metaanalysis of randomized controlled trials showed that EVR use with CNI minimization is associated with improved renal function at 12 months without increased risk of biopsyproven ACR, but with higher risk of infections [41].

The ab initio administration of EVR also avoids many CNI-related toxicity effects, since in our series it was associated with lower incidence of new onset arterial hypertension and beneficial effects on IDDM. Although the incidence of new onset IDDM was similar in both groups, $30 \%$ of recipients treated with EVR were able to withdraw insulin.

In our study, the drug's toxicity profile was comparable with data from other EVR trials [42]. The most frequently observed EVR-related adverse event was an increase in triglyceride and cholesterol blood levels in patients receiving EVR, which was easily managed by drug therapy. Drugrelated side effects were mainly resolved by dose adjustment, except for one case of leukopenia which required EVR withdrawal.

The main limitations the present study are represented by its retrospective nature and the small cohort of patients. Our current analysis, however, appears to corroborate the results 
previously described in our entire cohort of LT recipients treated with EVR from day 1 after LT [19]. Notwithstanding, these encouraging data clearly need confirmation within randomized trials to assess the favorable impact of EVR ab initio in terms of both safety and efficacy.

\section{CONCLUSION}

In conclusion, these data are the first that compare the clinical outcomes of LT recipients treated with EVR-based IS versus Tac at a standard dose immediately after LT. The results suggest that the association of EVR with low-dose Tac ab initio after LT without corticosteroids and induction therapy seems to be safe and effective in terms of preservation of renal function and showed a good management of CNI side effects. It may therefore be considered a valid option immediately after surgery in selected recipients at high risk for renal impairment or CNI comorbidities.

\section{REFERENCES}

[1] Gonwa TA, Mai ML, Melton LB, Hays SR, Goldstein RM, Levy MF, et al. End-stage renal disease (ESRD) after orthotopic liver transplantation (OLTX) using calcineurin-based immunotherapy: risk of development and treatment. Transplantation 2001;72(12):1934-9.

[2] Ojo AO, Held PJ, Port FK, Wolfe RA, Leichtman AB, Young EW, et al. Chronic renal failure after transplantation of a nonrenal organ. N Engl J Med 2003;349(10):931-40.

[3] Bechstein WO. Neurotoxicity of calcineurin inhibitors: impact and clinical management. Transpl Int 2000;13(5):313-26.

[4] Guba M, Graeb C, Jauch KW, Geissler EK. Pro- and anticancer effects of immunosuppressive agents used in organ transplantation. Transplantation 2004;77(12):1777-82.

[5] Tjon AS, Sint Nicolaas J, Kwekkeboom J, de Man RA, Kazemier G, Tilanus HW, et al. Increased incidence of early de novo cancer in liver graft recipients treated with cyclosporine: an association with $\mathrm{C} 2$ monitoring and recipient age. Liver Transpl 2010;16(7):837-46.

[6] Vincenti F, Friman S, Scheuermann E, Rostaingd L, Jenssene T, Campistolf JM, et al., DIRECT (Diabetes Incidence after Renal Transplantation: Neoral C Monitoring Versus Tacrolimus) Investigators. Results of an international, randomized trial comparing glucose metabolism disorders and outcome with cyclosporine versus tacrolimus. Am J Transplant 2007;7(6):1506-14.

[7] Bianchi G, Marchesini G, Marzocchi R, Pinna AD, Zoli M. Metabolic syndrome in liver transplantation: relation to etiology and immunosuppression. Liver Transpl 2008;14(11):1648-54.

[8] Klintmalm GB, Nashan B. The role of mTOR inhibitors in liver transplantation: reviewing the evidence. J Transplant 2014;2014:845438.

[9] De Simone P, Nevens F, De Carlis L, Metselaar HJ, Beckebaum S, Saliba F, et al. Everolimus with reduced tacrolimus improves renal function in de novo liver transplant recipients: a randomized controlled trial. Am J Transplant 2012;12:3008.

[10] Fischer L, Klempnauer J, Beckebaum S, Metselaar HJ, Neuhaus P, Schemmer P, et al. A randomized, controlled study to assess the conversion from calcineurin-inhibitors to everolimus after liver transplantation - PROTECT. Am J Transplant 2012;12:1855.

[11] Teperman L, Moonka D, Sebastian A, Sher L, Marotta P, Marsh C, et al. Calcineurin inhibitor-free mycophenolate mofetil/sirolimus maintenance in liver transplantation: the randomized spare-the-nephron trial. Liver Transpl 2013;19:675.

[12] Fischer L, Saliba F, Kaiser G, De Carlis L, Metselaar HJ, De Simone P, et al. Three-year outcomes in de novo liver transplant patients receiving everolimus with reduced tacrolimus: follow-up results from a randomized, multicenter study. Transplantation 2015;99:1455-62.

[13] Ram Peddi V, Wiseman A, Chavin K, Slakey D, et al. Review of combination therapy with $\mathrm{mTOR}$ inhibitors and tacrolimus minimization after transplantation. Transplant Rev 2013:27:97-107.

[14] Sterneck M, Kaiser GM, Heyne N, Richter N, Rauchfuss F, Pascher A, et al. Everolimus and early calcineurin inhibitor withdrawal: 3-year results from a randomized trial in liver transplantation. Am J Transplant 2014;14:701-10.

[15] Masetti M, Montalti R, Rompianesi G, Codeluppi M, Gerring R, Romano A, et al. Early withdrawal of calcineurin inhibitors and everolimus monotherapy in de novo liver transplant recipients preserves renal function. Am J Transplant 2010;10: 2252-62.

[16] Cillo U, Vitale A, Salizzoni M, Coledan M, Rossi G, Baccarani U, et al. Early introduction of everolimus in de novo liver transplantation: 3-months final results (primary endpoint) of a multicenter randomized clinical trial (EPOCAL). ILTS 2014. Abstract 0-9, Abstract book; 2014.

[17] Herden U, Galante A, Fischer L, Pischke S, Li J, et al. Everolimus initiation immediately after liver transplantation: a single-center experience. Ann Transplant 2016;21:77-85.

[18] Levy G, Schmidli H, Punch J, Tuttle-Newhall E, Mayer D, Neuhaus P, et al. Safety, tolerability, and efficacy of everolimus in de novo liver transplant recipients: 12 - and 36-month results. Liver Transplant 2006;12:1640-8.

[19] Manzia TM, Angelico R, Toti L, Belardi C, Cillis A, Quaranta C, et al. The efficacy and safety of mammalian target of rapamycin inhibitors ab initio after liver transplantation without corticosteroids or induction therapy. Dig Liver Dis 2016;48(3): $315-20$.

[20] TruneČka P, Klempnauer J, Bechstein WO, Pirenne J, Friman S, Zhao A, et al. Renal function in de novo liver transplant recipients receiving different prolonged-release tacrolimus regimens-the diamond study. Am J Transplant 2015;15(7):1843-54.

[21] Marinova M, Artusi C, Brugnolo L, Antonelli G, Zaninotto M, Plebani M. Immunosuppressant therapeutic drug monitoring by LC-MS/MS: workflow optimization through automated processing of whole blood samples. Clin Biochem 2013;46: $1723-7$.

[22] Banff schema for grading liver allograft rejection: an international consensus document. Hepatology 1997;25:658.

[23] Banff Working Group, Demetris AJ, Adeyi O, et al. Liver biopsy interpretation for causes of late liver allograft dysfunction. Hepatology 2006;44(2):489-501.

[24] Ishak K, Baptista A, Bianchi L, Callea F, De Groote J, Gudat F, et al. Histological grading and staging of chronic hepatitis. J Hepatol 1995;22:696.

[25] First MR, Dhadda S, Croy R, Holman J, Fitzsimmons WE. New-onset diabetes after transplantation (NODAT): an evaluation of definitions in clinical trials. Transplantation 2013;96:58.

[26] Gurk-Turner C, Manitpisitkul W, Cooper M. A comprehensive review of everolimus clinical reports: a new mammalian target of rapamycin inhibitor. Transplantation 2012;94:659-68.

[27] Trotter JF, Lizardo-Sanchez L. Everolimus in liver transplantation. Curr Opin Organ Transplant 2014;19(6):578-82.

[28] De Simone P, Metselaar HJ, Fischer L, Dumortier J, Boudjema K, Hardwigsen J, et al. Conversion from a calcineurin inhibitor to everolimus therapy in maintenance liver transplant recipients: a prospective, randomized, multicenter trial. Liver Transpl 2009;15(10):1262-9.

[29] Pillebout E, Nochy D, Hill G, Conti F, Antoine C, Calmus Y, et al. Renal histopathological lesions after orthotopic liver transplantation (OLT). Am J Transplant 2005;5:1120.

[30] Holdaas H, Rostaing L, Serón D, Cole E, Chapman J, Fellstrøm B, et al. Conversion of long-term kidney transplant recipients from calcineurin inhibitor therapy to everolimus: randomized, multicenter, 24-month study. Transplantation 2011;92:410. 
[31] Schena FP, Pascoe MD, Alberu J, del Carmen Rial M, Oberbauer R, Brennan DC, et al. Conversion from calcineurin inhibitors to sirolimus maintenance therapy in renal allograft recipients: 24-month efficacy and safety results from the CONVERT trial. Transplantation 2009;87:233.

[32] De Simone P, Fagiuoli S, Cescon M, De Carlis L, Tisone G, Volpes R, et al. Use of everolimus in liver transplantation: recommendations from a working group. Transplantation 2017;101(2): 239-51.

[33] Saliba F, De Simone P, Nevens F, De Carlis L, Metselaar HJ, Beckebaum S, et al., H2304 Study Group. Renal function at 2 years in liver transplant patients receiving everolimus: results of a randomized, multicenter study. Am J Transplant 2013;13(7):1734-45.

[34] De Simone P, Saliba F, Dong G, Escrig C, Fischer L. Do patient characteristics influence efficacy and renal outcomes in liver transplant patients receiving everolimus? Clin Transplant 2016;30(3):279-88.

[35] van Gelder T, Fischer L, Shihab F, Shipkova M. Optimizing everolimus exposure when combined with calcineurin inhibitors in solid organ transplantation. Transplant Rev (Orlando). $2017 \mathrm{Feb}$ 27. pii: S0955-470X(16)30108-2. https://doi.org/10.1016/j.trre.2017. 02.007. [Epub ahead of print] Review.

[36] Willuweit K, Heinold A, Rashidi-Alavijeh J, Heinemann FM, Horn PA, Paul A, et al. Immunosuppression with
mTOR inhibitors prevents the development of donor-specific antibodies after liver transplant. Clin Transplant 2017 Mar 26. https:// doi.org/10.1111/ctr.12974 [Epub ahead of print].

[37] Dumortier J, Dharancy S, Calmus Y, Duvoux C, Durand F, Salamé E, et al. Use of everolimus in liver transplantation: the French experience. Transplant Rev (Orlando) 2016;30(3):161-70.

[38] Sharma P, Welch K, Eikstadt R, Marrero JA, Fontana RJ, Lok AS. Renal outcomes after liver transplantation in the model for end-stage liver disease era. Liver Transplant 2009;15:1142-8.

[39] Burra P, Senzolo M, Masier A, Prestele H, Jones R, Samuel D, et al. Factors influencing renal function after liver transplantation. Results from the MOST, an international observational study. Dig Liver Dis 2009;41:350-6.

[40] O'Riordan A, Wong V, McCormick PA, Hegarty JE, Watson AJ. Chronic kidney disease post-liver transplantation. Nephrol Dial Transplant 2006;21:2630-6.

[41] Lin M, Mittal S, Sahebjam F, Rana A, Sood GK. Everolimus with early withdrawal or reduced-dose calcineurin inhibitors improves renal function in liver transplant recipients: a systematic review and meta-analysis. Clin Transplant 2017 Feb;31(2). https:// doi.org/10.1111/ctr.12872. Epub 2017 Jan 18.

[42] Pengel LH, Liu LQ, Morris PJ. Do wound complications or lymphoceles occur more often in solid organ transplant recipients on mTOR inhibitors? A systematic review of randomized controlled trials. Transplant Int 2011;24:1216-30. 